\title{
ROLE OF CT SCAN IN PAEDIATRIC PATIENTS
}

\author{
R. K. Jayshree1, O. Guneshwar Singh ${ }^{2}$
}

${ }^{1}$ Assistant Professor, Department of Radiodiagnosis, Jawaharlal Nehru Institute of Medical Sciences, Imphal. ${ }^{2}$ Associate Professor, Department of Orthopaedics, Jawaharlal Nehru Institute of Medical Sciences, Imphal.

\section{ABSTRACT}

\section{BACKGROUND}

The aim of this study was to highlight the role of CT scan in paediatric patients and as well as the risk involved.

\section{MATERIALS AND METHODS}

The study was carried out retrospectively over a period between August 2014 to June 2016 in the Department of Radiodiagnosis, Jawaharlal Nehru Institute of Medical Sciences, Imphal, Manipur.

\section{RESULTS}

CT scan of head was the most commonly carried out procedure and it was done mostly for head trauma. In 11.60 percent of the cases, there were bony fracture and internal bleeding in 2.47 percent. Scalp injury with no bony involvement were observed in 18.02 percent of the cases and in 60.25 percent of the cases no abnormalities were detected.

\section{CONCLUSION}

CT scan detects skull fractures or bleeding in brain with high degree of accuracy. However, children especially infants have developing brains and so injudicious use of CT scan increases the risk of cancer due to ionising radiation.

\section{KEYWORDS}

CT Scan, Ionising Radiation, MRI, ICP, EDH, TBI, DAI, NICE.

HOW TO CITE THIS ARTICLE: Jayshree RK, Singh OG. Role of CT scan in paediatric patients. J. Evolution Med. Dent. Sci. 2016; 5 (89): 6614-6617, DOI: $10.14260 / J e m d s / 2016 / 1496$

\section{BACKGROUND}

CT scan is a non-invasive, fast imaging procedure; it produces real time image with high degree of accuracy. It generates 3D image which can be reformatted in different planes and windows. CT scan has got very high sensitivity and specificity in trauma cases. However, it produces ionising radiation, which is harmful to the developing brain in children.

According to "The Essential Physics of Medical Imaging" one head CT scan for a child-based on youngster's age is the equivalent of approximately 140 chest x-rays. Radiation exposure in the brains of developing children is of particular concern and must be weighed carefully against the risk of traumatic brain injury that could cause permanent damage or death if not identified in time.

Lee and Kupperman ${ }^{1}$ noted that if the guidelines are applied appropriately, the use of unnecessary CT scans could be reduced significantly.

Head CT scan is recommended to evaluate head injuries because it is fast, easily available in most centres and is good in identifying recent severe injuries. Young children may need to be sedated only briefly, i.e. less than 15 minutes in most cases to obtain the desired result. MRI (Magnetic Resonance Imaging) of the brain is not a test of good choice for recent brain injury and it is usually not available in many centres.

Financial or Other, Competing Interest: None.

Submission 17-10-2016, Peer Review 31-10-2016,

Acceptance 02-11-2016, Published 05-11-2016.

Corresponding Author:

Dr. O. Guneshwar Singh,

Nepra Menjor Mamang Leikai,

Sagolband,

Imphal.

E-mail: singhguneshwar@ymail.com

DOI: $10.14260 /$ jemds/2016/1496
In addition, while doing MRI the child has to remain completely still for at least 30 minutes requiring prolonged sedation or general anaesthesia.

Most parents assume that their child should undergo imaging tests after a head injury. The real purpose of imaging tests such as CT head is to determine if there is bleeding inside or around the brain, a skull fracture or other serious brain injuries. Most children with a minor head injury do not require an imaging test, because the risk of a serious brain injury is small. So CT scan should be performed only when there is concern about a serious brain injury in order to avoid unnecessary exposure to radiation. CT scan may be recommended when the following signs or symptoms of brain injury are present. They include:

- Prolonged loss of consciousness.

- Persistent or severe memory loss, confusion.

- Persistent vomiting.

- Seizure.

- Severe, persistent or worsening headache.

- Suspicion of intentional injury (Child abuse).

- Behavioural change (e.g. lethargy, decreased alertness, extreme irritability).

- Signs of a skull fracture or bulging fontanelle.

- Abnormal findings on neurological examination.

- Significant scalp swelling or bruise in a very young infant.

- Blood or clear fluid oozing from the ears or nose.

- Incident with higher risk of head injury.

- High speed motor vehicle accident.

- Fall from great heights.

- Being hit by a high speed, heavy or sharp object, etc.

\section{MATERIALS AND METHODS}

The study was carried out in the Department of Radiodiagnosis, Jawaharlal Nehru Institute of Medical 
Sciences, Imphal, during the period between August 2014 and June 2016. Sixty four slice CT scan was used for the study. Six hundred and four consecutive cases of CT scan in children upto the age of 14 years were studied. The cases analysed were referred from the Dept. of Orthopaedics, General Surgery, Paediatrics and Emergency Services of the Institute. History as given in the investigation form/case sheets were noted. The particular sites for which CT was to be taken such as head, PNS, temporal, abdomen, chest, face, musculoskeletal, neck, orbit, etc. were noted. For CT scan head the cases were recorded in 3 groups, viz. 0 to 5 years, 6 to 10 years, 11 to 14 years. Sex wise distribution was also done. Pattern of CT findings for each site were also recorded and analysed.

For aggressive child trichlorophos sodium syrup was given orally 30 minutes before the procedure. The dose given was 25 $\mathrm{mg} / \mathrm{kg}$ body weight for infants, for children of 1-5 years it was 250 - $500 \mathrm{mg}$ and $500-1000 \mathrm{mg}$ for children above 5 years. Other parts of the body like genital organs were shielded using lead sheet.

\section{RESULTS}

The age and sex distribution of 604 children for which CT scan was undertaken is given in Table I. There were 192 (31.78\%) children in the age group of 0 - 5 years, out of which 112 were male and 80 were female. There were 181 (29.96\%) children in the age group of 6 - 10 years, out of which 127 were male and 54 were female. In the age group of 11 - 14 years, there were 231 (38.24\%) children of which 142 were male and 89 were female. Total number of male children were 381 $(63.08 \%)$ and total number of female children were 223 (36.92\%).

Table II shows the distribution of sites and findings of CT scan of head, which was taken for $405(67.05 \%)$ of the total cases followed by that of temporal area - 58 (9.60\%) cases and PNS - $50(8.27 \%)$ cases. CT for musculoskeletal injuries were responsible for $31(5.13 \%)$ cases.

Out of 405 cases of CT scan head, normal scan was found in $244(60.25 \%)$ cases, minimal scalp injury in $73(18.02 \%)$ cases, bony fracture in $47(11.60 \%)$, internal bleeding in 10 $(2.47 \%)$, congenital lesion in $11(2.72 \%)$, infection in 8 $(1.96 \%)$ and tumour and infarct in $6(1.48 \%)$ cases each. Of the 47 cases of bony fracture, most of the cases were subtle linear fracture without obvious extradural haemorrhage; however, 10 cases of internal bleeding were associated with bony fracture. Of the 10 cases of internal bleeding 5 cases were of extradural haematoma along the fracture line, 2 cases with extradural as well as subdural haemorrhage and 3 cases had cerebral contusion with subarachnoid and extradural haemorrhages.
Of the 11 congenital lesions 2 cases were of corpus callosum agenesis, 3 cases of arachnoid cyst in the middle cranial fossa, 1 case of hydrocephalus and 5 cases of persistent cavum septum pellucidum. Of the 8 cases of infection, there were 4 cases of granulomas, 2 cases of neurocysticercosis and 2 cases of meningoencephalitis.

Among 6 cases of tumour, 2 cases were of brain stem glioma, 2 cases of low-grade astrocytoma, 1 case of glioblastoma multiforme and 1 case of medulloblastoma. Most of the infarct cases were of hypoxic-ischaemic infarcts.

Table III shows the age wise distribution for which CT scan was taken for each site. Maximum number of CT scan of head were taken in age group of 0 - 5 years followed by 6 - 10 years group, 149 cases $(36.79 \%)$ of CT head was taken in the age of 0 - 5 years, whereas 138 cases $(34.07 \%)$ were taken the age group of 6 - 10 years. For CT scan of PNS, maximum scans were taken in the age group of 11 - 14 years, 39 (78\%) cases.

Maximum cases of CT scan taken for musculoskeletal injuries were in the age group 11 - 14 years (51.62\%) followed by 6 - 10 years $(41.93 \%)$.

CT of paranasal sinuses was taken in $50(8.27 \%)$ of the cases. Infection (Rhinosinusitis) was the commonest finding in 47 (94\%) cases. CT scan for temporal bone was done in 58 $(9.60 \%)$ cases. The most common finding was infection and found in $30(51.72 \%)$ cases. In temporal bone tumour, 5 cases were of fibrous dysplasia, 2 cases of osteoma of external auditory canal and 1 case of glomus tympanicum. Of the 11 cases of chest infection, 7 cases were of pulmonary tuberculosis with mediastinal lymphadenopathy, 2 cases of pneumothorax and 2 cases of lobar pneumonia with pleural effusion.

In abdominal CT the 3 cases were of minimal soft tissue swelling, 2 cases were of infection, 1 of appendicitis and another of intestinal tuberculosis with ascites. There was 1 case of Wilms' tumour and 1 case of neuroblastoma.

In CT scan done for musculoskeletal trauma, the commonest finding was fracture of long bones and there was 1 case of osteomyelitis tibia.

\begin{tabular}{|c|c|c|c|}
\hline $\begin{array}{c}\text { Age } \\
\text { Group }\end{array}$ & Male & Female & Total (\%) \\
\hline 0-5 yrs. & 112 & 80 & $\begin{array}{c}192 \\
(31.78 \%)\end{array}$ \\
\hline 6-10 yrs. & 127 & 54 & $\begin{array}{c}181 \\
(29.96 \%)\end{array}$ \\
\hline $11-14$ yrs. & 142 & 89 & $\begin{array}{c}231 \\
(38.24 \%)\end{array}$ \\
\hline Total & $\begin{array}{c}381 \\
(63.08 \%)\end{array}$ & $\begin{array}{c}223 \\
(36.92 \%)\end{array}$ & 604 \\
\hline \multicolumn{4}{|c|}{ Table I. Age \& Sex Distribution } \\
\hline
\end{tabular}

\begin{tabular}{|c|c|c|c|c|c|c|c|c|c|}
\hline Site & Normal & $\begin{array}{c}\text { Soft Tissue } \\
\text { Swelling/ } \\
\text { Scalp } \\
\text { Swelling }\end{array}$ & $\begin{array}{c}\text { Bony } \\
\text { Fracture }\end{array}$ & $\begin{array}{c}\text { Internal } \\
\text { Bleeding }\end{array}$ & Infection & Congenital & Tumour & Infarct & Total \\
\hline Head & 244 & 73 & 47 & 10 & 8 & 11 & 6 & 6 & $\begin{array}{c}405 \\
(67.05 \%)\end{array}$ \\
\hline PNS & 2 & & 1 & & 47 & & & 50 \\
$(8.28 \%)$ \\
\hline $\begin{array}{c}\text { Temporal } \\
\text { bone }\end{array}$ & 20 & & & & 30 & & 8 & $58 \%(5)$ \\
\hline
\end{tabular}




\begin{tabular}{|c|c|c|c|c|c|c|c|c|}
\hline $\begin{array}{c}\text { Face \& } \\
\text { orbit }\end{array}$ & 8 & 1 & & & & & $9(1.49 \%)$ \\
\hline Chest & 16 & & & & 11 & & & $\begin{array}{c}27 \\
(4.47 \%)\end{array}$ \\
\hline Abdomen & 14 & 3 & & & 2 & & 2 & $\begin{array}{c}21 \\
(3.47 \%)\end{array}$ \\
\hline Neck & & & & & 2 & 1 & & $3(0.49 \%)$ \\
\hline $\begin{array}{c}\text { Musculo- } \\
\text { skeletal }\end{array}$ & 10 & 9 & 11 & & 1 & & & 31 \\
\hline \multicolumn{7}{|c|}{ Table II. CT Pattern (Findings) } \\
\hline
\end{tabular}

\begin{tabular}{|c|c|c|c|c|}
\hline \multirow{2}{*}{ Site } & \multicolumn{3}{|c|}{ Age Group } & \multirow{2}{*}{ Total } \\
\cline { 2 - 4 } & $\mathbf{0 - 5}$ & $\mathbf{6 - 1 0}$ & $\mathbf{1 1 - 1 4}$ & \\
\hline Head & 149 & 138 & 118 & 405 \\
\hline PNS & 3 & 8 & 39 & 50 \\
\hline Temporal bone & 22 & 10 & 26 & 58 \\
\hline Face \& orbit & 1 & 2 & 3 & 6 \\
\hline Chest & 9 & 5 & 13 & 27 \\
\hline Abdomen & 2 & 3 & 16 & 21 \\
\hline Neck & 2 & 1 & & 3 \\
\hline Musculoskeletal & 2 & 13 & 16 & 31 \\
\hline Orbit Table III. Distribution of Cases & 3 \\
\hline \multicolumn{5}{|r}{} \\
\hline \multicolumn{7}{|l}{} \\
\hline
\end{tabular}

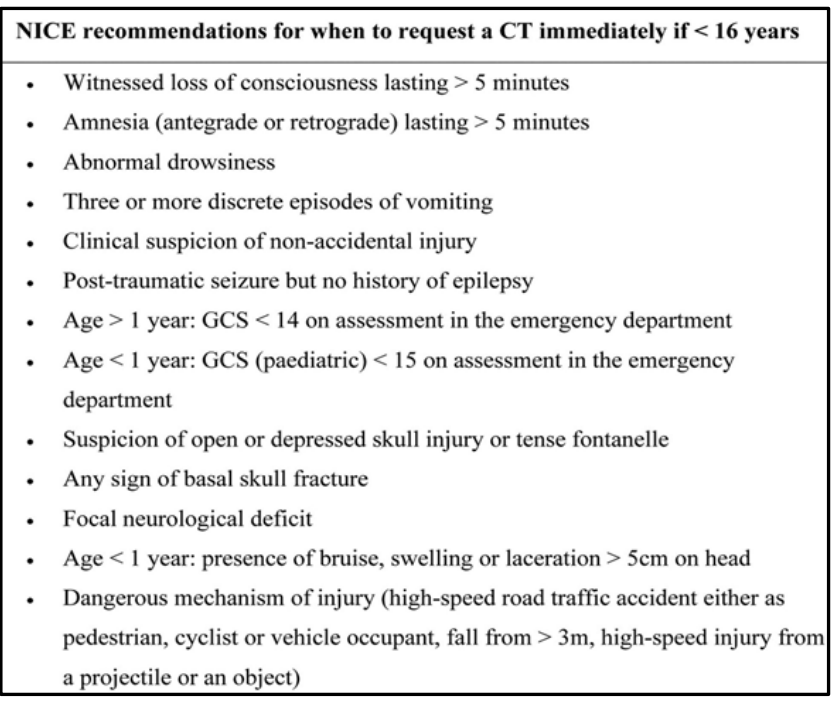

\section{Table IV}

\section{DISCUSSION}

Head injury during infancy and young childhood has been documented to be the most common cause of death. ${ }^{2}$ Head injury has been found to be most common in the age of $6-10$ years, which is similar to a study conducted by P. Sharma ${ }^{3}$ at Angola and Goa, India. But in a similar study conducted by Bhargava et $\mathrm{al}^{4}$ it was found to be more common in the age group of 1 - 5 years.

Tomberg et $\mathrm{al}^{5}$ conducted a study in 1996 regarding paediatric head injury and they found that the most frequent finding in CT was diffuse brain swelling, ventricular and cisternal compression or obliteration. ${ }^{6}$ They also found that third ventricular compression is a more sensitive CT index of increased ICP, which along with cisternal obliteration indicates worse prognosis.

The CT scan appearance of diffuse swelling may develop more readily in children because of less amount of cerebrospinal fluid available for displacement; however, diffuse swelling may have a relatively benign course, unless there is severe primary injury or a secondary hypotensive insult.7,8

Skull fractures result from direct impact to calvarium and are important because of their association with intracranial injury, which is the leading cause of traumatic death in childhood.9,10 In the present study, fracture of skull bone was found in $11.60 \%$ of cases and they are associated with high mortality. Incidence of skull fractures ranged from 2 to 20 percent in a study conducted by Schetzmansa et al ${ }^{11}$ of all types of paediatric skull fractures, linear fracture is the most common type and usually involve the parietal bone as seen in the study.

In the present study, CT scan was normal in more than $60 \%$ of the cases and minimal scalp injury (soft tissue injury) was found in about $18 \%$ of the cases.

Placket TP et al in a study of 631 cases of paediatric traumatic brain injury for which CT head was done observed that CT scan was normal in $63 \%$ of the cases, skull fracture (non-displaced) in $7 \%$ of the cases and $30 \%$ has an intracranial haemorrhage or displaced skull fracture.

Often CT scans are not necessary. If a child has mild concussion, a CT scan probably may not be helpful because the results are usually normal. But CT scans are better for injuries like skull fractures or bleeding in the brain. A concussion is not caused by bleeding in the brain and so a doctor should order a CT scan if it is likely that the child has a skull fracture or bleeding. The doctor should ask in detail about the accident and symptoms listed below and should also look for signs of skull fracture such as black eyes, bleeding, etc.

Some of the Accidents likely to cause Serious Head Injury are

- Motor vehicle accident.

- Fall from height of 3 or more feet from the ground.

- Falling down from five or more stairs.

- Falling from a bicycle without a helmet.

\section{Some Symptoms which Suggests Serious Head Injury are}

- Unconsciousness.

- Tingling on one side of the body.

- Being dizzy or losing balance.

- Loss of vision or hearing.

- Headache that gets worse.

- Very sleepy or irritable.

Therefore, National Institute for Health and Care Excellence (NICE) guidelines, which aimed at identifying children at risk of clinically significant brain injury should be followed. With the use of these guidelines, the risk of missing intracranial injury and overuse of CT scan can be avoided to a great extent. NICE 2007 guidelines recommend immediate CT scan, if one of the listed recommendations given in Table IV is 
present. The more recent 2014 guidelines include a second tier of indicators, which permit a 4-hour observation followed by CT scan if the child deteriorates. ${ }^{12}$

\section{CONCLUSION}

The present study shows that in more than $60 \%$ of the cases, CT scan report are normal. CT scan is one of the most commonly used modality for diagnosis of trauma, especially head trauma.

\section{The Advantages of CT Scan are}

1. It plays a vital role in initial diagnosis and followup studies of TBI in centres, where MRI is not readily available.

2. CT scan is a very good screening tool in minor head injury.

3. Available easily in many centres.

4. Sedation has to be done for a short period of about 15 minutes only. Followup can be advised using MRI and ultrasound, especially in tertiary centres.

However, diffuse axonal injury is poorly evaluated by CT scan. MRI is a valuable adjunct to CT scan in the followup cases. Radiograph have a limited role in assessing intracranial lesions in traumatic brain injury. But recent studies indicate that exposure to ionising radiation associated with CT scan increases risk of developing cancer. These may be as high as 1 case of lethal cancer for every $1000 \mathrm{CT}$ scans performed in a young child. ${ }^{13}$ Risk of leukaemia and brain tumour have also been reported from a large UK Cohort study. ${ }^{14}$ Due to risk of ionising radiation, CT scan should be limited to acute trauma cases with significant neurologic impairment.

It is very essential to minimise exposure to ionising radiation as far as possible in children whose brain is developing. The risk of developing a tumour from exposure to a given dose of radiation is greater in childhood. Various strategies can be used to reduce exposure to ionising radiation. Therefore, it is better to avoid unnecessary tests and tests that are not indicated to choose an alternative test that does not use ionising radiation. At the same time, series of measures that minimise the dose of radiation can be undertaken such as avoiding repeat tests, using appropriate projections, using shields, adjusting the protocol (mA's, KV or pitch) to the patient's body volume, etc.

In China about $33.6 \%$ of clinicians reported that CT scan in suspected head injury is being ordered to protect themselves against medical lawsuits in the future. They also reported that there is no clear cut guidelines regarding treatment of paediatric TBI.

In order to avoid risk of radiation and sedation in asymptomatic patients of 3 to 24 months with scalp haematoma, a screening skull radiograph may be done. If the screening skull radiograph shows a fracture, then a CT scan head should be performed.

Hence, CT scan in children should be done only when there is evidence of clinically significant brain injury.

\section{REFERENCES}

1. Kuppermann N, Holmes JF, Dayan PS, et al. Identification of children at very low risk of clinically-important brain injuries after head trauma: a prospective cohort study. Lancet 2009;374(9696):1160-70.

2. Luerssen TG, Klauber MR, Marshall LF. Outcome from head injury related to patient's age. A longitudinal prospective study of adult and pediatric head injury. Journal of Neurosurgery 1988;68(3):409-16.

3. Sharma P. Role of computed tomographic scanning in pediatric head injury: an observational cohort of data of 60 patients. Open Journal of Emergency Medicine 2015;3(4):45-9.

4. Bhargava P, Singh R, Prakash B, et al. Pediatric head injury: an epidemiological study. Journal of Pediatric Neurosciences 2011;6(1):97-8.

5. Tomberg T, Rink U, Pikkoja E, et al. Computerized tomography and prognosis in paediatric head injury. Acta Neurochirurgica 1996;138(5):543-8.

6. Bruce DA, Alavi A, Bilaniuk L, et al. Diffuse cerebral swelling following head injuries in children: the syndrome of "malignant brain edema". Journal of Neurosurgery 1981;54(2):170-8.

7. Teasdale E, Cardoso E, Galbraith S, et al. CT scan in severe diffuse head injury: physiological and clinical correlations. Journal of Neurology Neurosurgery \& Psychiatry 1984;47(6):600-3.

8. Lang DA, Teasdale GM, Macpherson P, et al. Diffuse brain swelling after head injury: more often malignant in adults than children? Journal of Neurosurgery 1994;80(4):67580.

9. Quayle KS, Jaffe DM, Kuppermann N, et al. Diagnostic testing for acute head injury in children: when are head computed tomography and skull radiographs indicated? Pediatrics 1997;99(5):E11.

10. Shane SA, Fuchs SM. Skull fractures in infants and predictors of associated intracranial injury. Pediatric Emergency Care 1997;13(3):198-203.

11. Kraus JF, Fife D, Conroy C. Pediatric brain injuries: the nature, clinical course, and early outcomes in a defined united states' population. Pediatrics 1987;79(4):501-7.

12. National Institute for Health and Clinical Excellence (NICE). Head injury: Triage, assessment, investigation and early management of head injury in children, young people and adults. 2014. http://www. nice. org.uk/ guidance/ cg176.

13. Rice HE, Frush DP, Farmer D, et al. Review of radiation risks from computed tomography: essentials for the pediatric surgeon. Journal of Pediatric Surgery 2007;42(4):603-7.

14. De Gonzalez AB, Salotti JA, McHugh K, et al. Relationship between paediatric CT scans and subsequent risk of leukaemia and brain tumours: assessment of the impact of underlying conditions. Br J Cancer 2016;114(4):388-94. 